\title{
Bestens gerüstet mit innovativen Oberflächen
}

$\mathrm{D}$ er Oberfläche kommt im Maschinenbau eine besondere, wertschöpfende Bedeutung zu, denn im Praxiseinsatz muss sie hohe Anforderungen erfüllen. Äußere Einflüsse - wie zum Beispiel chemische oder mechanische Belastung, Witterung und extreme Temperaturunterschiede - können die Funktion beeinträchtigen, bis hin zum kompletten Bauteilversagen.

Leistungsfähige und ressourcenschonend hergestellte Oberflächen werden zu einem entscheidenden Kosten- und Zeitfaktor in der Produktion. Die Oberflächentechnik begleitet dabei ein Produkt über den gesamten Lebenszyklus - von der Konstruktion und Werkstoffauswahl, über die Beschichtungsverfahren und -prozesse, bis hin zur Instandsetzung und Korrosion.

Die Anforderungen an die Oberflächenqualität erreichen im Maschinenbau ein ähnlich hohes Niveau wie in der Automobilindustrie. Und die Problemstellungen sind ganz ähnlich: Welches Lacksystem eignet sich für die individuelle Anwendung am besten und wie lässt sich trotz harscher Bedingungen eine optisch ansprechende Oberfläche und ein hoher Korrosionsschutz herstellen? Wie lässt sich eine höhere Prozesssicherheit und Ressourceneffizienz unter wirtschaftlichen Bedingungen sicherstellen?

Antworten bietet das aktuelle JOT Special „Oberflächentechnik im Maschinenbau". Es geht auch der Frage nach, wie Potenziale zur weiteren Optimierung ausgeschöpft werden können und stellt die dafür nötigen Verfahren und Produkte vor. Ergänzend dazu liefert das Heft vorab zur Premiere der DeburringExpo vom 13. bis 15. Oktober 2015 in Karlsruhe umfassende Informationen zu Produkten und Neuentwicklungen der Entgrat- und Poliertechnologie.

Erstmalig erscheint das JOT Special komplett als Digitalmagazin. Über die Volltextsuche finden Sie zielgenau aktuelle Best-Practice-Lösungen, Grundlagenbeiträge und Produktinformationen. Unser Online-Angebot entwickeln wir ständig weiter und freuen uns über Fragen und Anregungen.

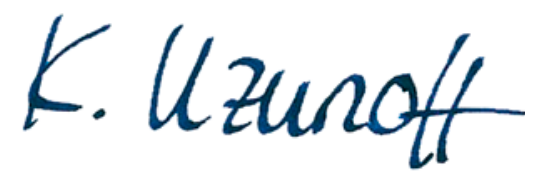

Kathrin Uzunoff

(Stellvertretende Chefredakteurin)

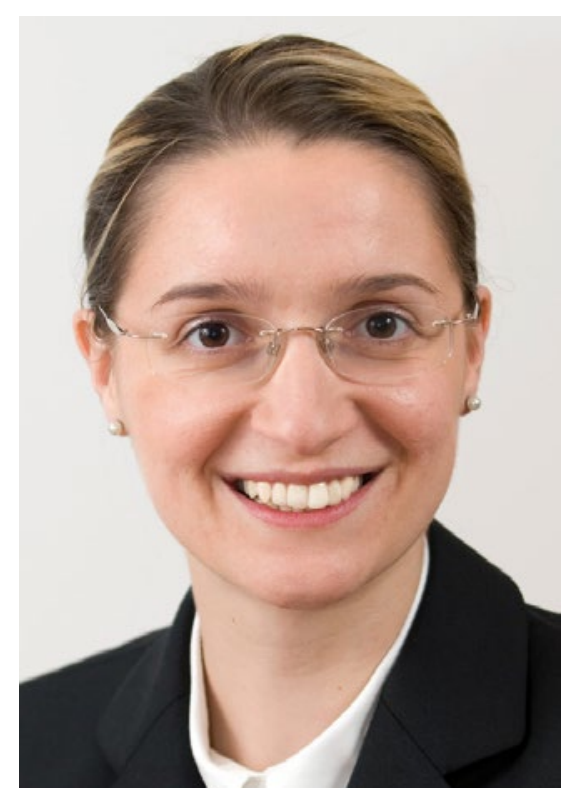

